\title{
Late functional outcomes after repair of tetralogy of Fallot with atrioventricular septal defect: A double case-match control study
}

\author{
Yasuhiro Kotani, MD, PhD, ${ }^{a}$ Devin Chetan, HBA, ${ }^{a}$ Naoki Ono, MD, ${ }^{b}$ Luc L. Mertens, MD, PhD, \\ Christopher A. Caldarone, MD, ${ }^{\mathrm{a}}$ Glen S. Van Arsdell, MD, ${ }^{\mathrm{a}}$ and Osami Honjo, MD, $\mathrm{PhD}^{\mathrm{a}}$
}

Objectives: We sought to elucidate late functional outcomes of the right ventricular outflow tract and atrioventricular valves after repair of tetralogy of Fallot with atrioventricular septal defect.

\begin{abstract}
Methods: From 1990 to 2010, the data from 41 patients who underwent repair were retrospectively reviewed. The median age at repair was 22.4 months (interquartile range, 10.8-41.6 months). Of the 41 patients, 13 (32\%) had received previous palliations. The preoperative anatomic differences, physiologic differences, and longterm functional outcomes were determined using a double case-matched control with isolated tetralogy of Fallot and isolated atrioventricular septal defect.
\end{abstract}

Results: The right ventricular outflow tract was reconstructed, with the pulmonary valve preserved in 23 patients $(56 \%)$. There were 3 early deaths and no late deaths. Survival was $92.1 \%$ at 15 years. During a median follow-up period of 5.9 years (interquartile range, 0.14-13.7 years), 29 reinterventions were performed in $13(32 \%)$ patients. Freedom from all reintervention at 15 years was $52.8 \%$. Of the 29 procedures, $12(41 \%)$ were related to the right ventricular outflow tract. Freedom from right ventricular outflow tract-related reintervention was greater in patients who had their pulmonary valve preserved $(95 \%$ vs $70 \%$ at 10 years; $P=.046)$. Reinterventions were performed for the atrioventricular valve in $2(5 \%)$ patients and subaortic stenosis in $1(2 \%)$ patient. Freedom from right ventricular outflow tract-related reintervention (tetralogy of Fallot with atrioventricular septal defect, $88.6 \%$ vs tetralogy of Fallot alone, $83.9 \%$ at 5 years; $P=.809)$ and atrioventricular valve/left ventricular outflow tract-related reintervention (tetralogy of Fallot with atrioventricular septal defect, $95.2 \%$ vs atrioventricular septal defect alone, $86.0 \%$ at 5 years; $P=.332$ ) were comparable between the tetralogy of Fallot with atrioventricular septal defect and matched control groups.

Conclusions: Late survival and atrioventricular valve function after repair of tetralogy of Fallot with atrioventricular septal defect were excellent. Pulmonary valve preservation and avoidance of an artificial conduit were associated with greater freedom from right ventricular outflow tract reintervention. In the current era, the surgically modified history of tetralogy of Fallot with atrioventricular septal defect is not significantly different from that of isolated tetralogy of Fallot or isolated atrioventricular septal defect. (J Thorac Cardiovasc Surg 2013;145:1477-84)

\section{Supplemental material is available online.}

Tetralogy of Fallot with atrioventricular septal defect (TOF/ AVSD) has unique anatomic features involving both inlet and outlet components of the ventricles (ie, the presence of the common atrioventricular valve $[\mathrm{AVV}]$, a large

\footnotetext{
From the Divisions of Cardiovascular Surgery ${ }^{\mathrm{a}}$ and Cardiology, ${ }^{\mathrm{b}}$ Labatt Family Heart Centre, Hospital for Sick Children and University of Toronto, Toronto, Ontario, Canada.

Disclosures: Authors have nothing to disclose with regard to commercial support. Read at the 38th Annual Meeting of The Western Thoracic Surgical Association, Maui, Hawaii, June 27-30, 2012.

Received for publication June 29, 2012; revisions received Dec 4, 2012; accepted for publication Jan 11, 2013; available ahead of print Feb 18, 2013.

Address for reprints: Osami Honjo, MD, PhD, Division of Cardiovascular Surgery, Hospital for Sick Children, 555 University Ave, Toronto, ON M5G 1X8, Canada (E-mail: osami.honjo@sickkids.ca).

0022-5223/\$36.00

Copyright $(2013$ by The American Association for Thoracic Surgery http://dx.doi.org/10.1016/j.jtcvs.2013.01.007
}

ventricular septal defect [VSD], an anteriorly deviated infundibular septum, and subsequent aortic override). ${ }^{1-3}$ This complex anatomy posed surgical challenges in the early era of staged repair, resulting in a high operative mortality of up to $15 \%$ to $20 \%{ }^{4-6}$ The paradigm shift to primary repair has improved survival in the current era. ${ }^{1,5,7-9}$ Nevertheless, the overall reintervention rate remains high, with estimates of $20 \%$ to $50 \%$ at 5 years after repair. ${ }^{7,9,10}$

Considering the anatomy involving the inlet and outlet components, the high reintervention rate in this entity is comprehensible. The reintervention rate for the right ventricular outflow tract (RVOT) in patients with isolated TOF has been $10 \%$ to $40 \%$ at 5 years. ${ }^{11-13}$ Approximately $10 \%$ to $15 \%$ of the patients who have undergone repair for isolated complete AVSD will require reintervention for their left AVV or left ventricular outflow tract (LVOT) at 5 years after repair. ${ }^{14,15} \mathrm{We}$ sought to determine whether the inlet and outlet components of patients with TOF/AVSD might have equivalent functional outcomes and similar 


$$
\begin{aligned}
& \text { Abbreviations and Acronyms } \\
& \text { AVSD = atrioventricular septal defect } \\
& \mathrm{AVV}=\text { atrioventricular valve } \\
& \text { IQR = interquartile range } \\
& \text { LVOT = left ventricular outflow tract } \\
& \text { PA = pulmonary artery } \\
& \text { PV = pulmonary valve } \\
& \text { RVOT = right ventricular outflow tract } \\
& \text { TOF/ = tetralogy of Fallot with atrioventricular } \\
& \text { AVSD septal defect } \\
& \text { VSD = ventricular septal defect }
\end{aligned}
$$

long-term reintervention rates compared with those with isolated TOF or isolated AVSD. To investigate this question, a double case-match study was performed comparing the anatomic characteristics and long-term RVOT and AVV function between patients with TOF/AVSD and isolated TOF or isolated AVSD.

\section{METHODS}

We retrospectively reviewed the data from all patients who had undergone surgical repair of TOF/AVSD from January 1990 to December 2010 at the Hospital for Sick Children (Toronto, Ontario, Canada). The research ethics board approved the study and waived the requirement for patient consent. Of the 41 patients, 38 had typical TOF/AVSD and 3 had more than $50 \%$ aortic override, defined as a double outlet right ventricle/AVSD. Also, 33 patients $(78 \%)$ had trisomy 21 . A complete preoperative profile is listed in Table 1. Our surgical strategy shifted from staged repair to primary repair in the mid-1990s. ${ }^{5}$ Twenty palliations were performed in 13 patients $(32 \%)$ to increase the pulmonary blood flow before definitive repair.

\section{Surgical Technique}

All repairs were done with mild (moderate in the early era) hypothermic cardiopulmonary bypass with bicaval cannulation. All but 1 patient underwent closure of septal defects with the standard 2-patch technique. The ventricular patch used was polyethylene terephthalate fabric (Dacron) or polytetrafluoroethylene fashioned into a comma shape. The cleft was completely closed with interrupted polypropylene sutures (Ethicon, Somerville, NJ) unless a patient had a functional parachute left AVV. Partial annuloplasty was typically performed. Closure of the atrial septal defect was achieved with autologous pericardium. The RVOT muscle resection was performed using a transatrial and pulmonary approach. Valvotomy and commissurotomy were routinely performed on the pulmonary valve (PV). Our institutional criteria to attempt the PV-sparing repair evolved over time. The policy in the past 15 years has been that PV preservation was attempted when the PV z-score was -3 to -4 or greater. The final decision to preserve the PV was determined by the intraoperative intracardiac pressure and transesophageal echocardiographic findings. A right ventricular systolic pressure of less than $70 \%$ was accepted. If a significant residual pressure gradient was present at the infundibular level rather than at the PV, a separate infundibular patch was placed. Primary transannular patch repair was performed in patients with a severely hypoplastic PV.

\section{Echocardiographic Evaluation}

The original echocardiographic images were evaluated by echocardiographic investigators (N.O., L.M.), who were unaware of the original echocardiographic report and clinical outcomes. The morphologies of the
AVVs, ventricles, RVOT, and LVOT were determined. AVV regurgitation and ventricular function were graded (AVV regurgitation, 0 , none/trivial; 1 , mild; 2 , mild + /moderate; and 3 , moderate $+/$ severe; and ventricular function, 0 , normal; 1 , mildly reduced; 2 , moderately reduced; and 3 , severely reduced). The ventricular dimensions and AVV annular dimensions were measured from the apical 4-chamber view and were indexed by the body surface area. The AVV index was calculated as the left AVV area divided by the total AVV area. ${ }^{16}$

\section{Case-Match Control}

Patients with isolated TOF or isolated AVSD were selected as casematch control patients. Three control patients were matched to each study patient according to the diagnosis. A single best fit was then chosen according PV size, indexed PV size, body weight, and body surface area at surgery for the TOF control patients. For the AVSD control patients, the best fit was chosen by the preoperative AVV regurgitation grade and AVV index. Of the 41 patients, $33(80 \%)$ completely met the matching criteria. The remaining 8 patients $(20 \%)$ were excluded from the case-match analysis, because they lacked complete echocardiographic review data.

\section{Outcome Assessment}

The effects of preoperative anatomic and physiologic status (as determined by the echocardiographic variables) on clinical and functional outcomes were analyzed. The clinical outcomes, including freedom from reintervention, were evaluated. These outcomes were also compared with respect to the surgical technique used (native PV preserved vs native PV not preserved). Freedom from reintervention and late functional outcomes, including RVOT (against isolated TOF group) and AVV and LVOT (against isolated AVSD group), were compared between patients with TOF/AVSD and matched control patients.

\section{Statistical Analysis}

Continuous data are presented as median (interquartile range [IQR]). Discrete data are presented as frequencies (percentage). Differences between the groups were analyzed using the Mann-Whitney $U$ test. Event frequencies were tested using the chi-square test or Fisher's exact test. Freedom from reintervention was analyzed using Kaplan-Meier analysis and a log-rank test. Competing risk outcomes were analyzed with the cumulative incidence function. Univariable predictors for RVOT reintervention were explored with Cox regression analysis. The variables that were significant at the $P \leq .10$ level on univariable analysis were included in a stepwise multivariable Cox regression model. Statistical analysis was performed using SPSS (version 17.0; IBM Corporation, Armonk, NY) statistical software.

\section{RESULTS \\ Preoperative Echocardiographic Findings}

The level of RVOT obstruction was subvalvular in 31 $(94 \%)$, valvular in $32(97 \%)$, supravalvular in $8(24 \%)$, and at the pulmonary arteries in $1(3 \%$; Table E1). The PV z-score and peak pressure gradient across the RVOT was -2.25 (IQR, -3.37 to 0.13 ) and $65 \mathrm{~mm} \mathrm{Hg}$ (IQR, $55-75 \mathrm{~mm} \mathrm{Hg}$ ), respectively. The ventricles and AVVs were well balanced in most patients (AVV index, 0.47; IQR, 0.45-0.48; Table E2). Twelve patients (36\%) had moderate or greater AVV regurgitation preoperatively.

\section{RVOT Reconstruction}

The RVOT was reconstructed with the PV preserved in 23 patients $(56 \%$; infundibular and main pulmonary artery 
TABLE 1. Perioperative profile

\begin{tabular}{|c|c|}
\hline Variable & Value \\
\hline \multicolumn{2}{|l|}{ Patient profile } \\
\hline Age (mo) & $22.4(10.8-41.6)$ \\
\hline Body weight $(\mathrm{kg})$ & $10.4(7.8-12.7)$ \\
\hline $\operatorname{BSA}\left(\mathrm{m}^{2}\right)$ & $0.48(0.43-0.52)$ \\
\hline \multicolumn{2}{|l|}{ Diagnosis } \\
\hline TOF/AVSD & $38(93)$ \\
\hline DORV/AVSD & $3(7)$ \\
\hline Trisomy 21 & $32(78)$ \\
\hline Previous operations & $\mathrm{n}=13$ \\
\hline Blalock-Taussig shunt & $10(24)$ \\
\hline PA valvotomy & $3(7)$ \\
\hline Surgical & $2(5)$ \\
\hline Balloon & $1(2)$ \\
\hline Pulmonary arterioplasty & $3(7)$ \\
\hline Transannular patch & $1(2)$ \\
\hline PA stent & $1(2)$ \\
\hline Glenn shunt & $1(2)$ \\
\hline Arteriovenous fistula & $1(2)$ \\
\hline \multicolumn{2}{|l|}{ Operative technique } \\
\hline \multicolumn{2}{|l|}{ TOF } \\
\hline PV preserved & $23(56)$ \\
\hline Infundibular patch only & $3(7)$ \\
\hline PA and infundibular patch & $11(27)$ \\
\hline PA patch only & $6(15)$ \\
\hline No patch & $3(7)$ \\
\hline Transannular patch & $11(27)$ \\
\hline PV implant & $3(7)$ \\
\hline Right ventricle to PA conduit & $4(10)$ \\
\hline \multicolumn{2}{|l|}{ AVSD } \\
\hline One-patch repair & $1(2)$ \\
\hline Two-patch repair & $40(98)$ \\
\hline \multicolumn{2}{|l|}{ Reintervention } \\
\hline All reintervention & $13(32)$ \\
\hline RVOT-related reintervention & $7(20)$ \\
\hline AVV-related reintervention & $2(5)$ \\
\hline LVOT-related reintervention & $1(2)$ \\
\hline
\end{tabular}

Data presented as median (interquartile range) or $\mathrm{n}(\%) . B S A$, Body surface area; TOF, tetralogy of Fallot; $A V S D$, atrioventricular septal defect; DORV, double outlet right ventricle; $R V O T$, right ventricular outflow tract; $P A$, pulmonary artery; $P V$, pulmonary valve; $A V V$, atrioventricular valve; $L V O T$, left ventricular outflow tract.

[PA] patch in 11 [27\%], infundibular patch only in $3[7 \%]$, main PA patch only in $6[15 \%]$, and no patch in $3[7 \%]$; Table 1). Repair with a transannular patch was performed in 11 patients $(27 \%)$. The RVOT in the 7 remaining patients was reconstructed with an artificial valve in $3(7 \%)$ and a conduit in $4(10 \%)$. The rate of PV preservation during the past 2 decades was similar (1990-1999, 14/27 [52\%]; 2000-2011, 9/14 [64\%]; $P=.447)$.

\section{Survival}

There were 3 early deaths and no late deaths. All 3 deaths occurred before 1998 and were from acute ventricular failure and low cardiac output. Two deaths were related to early reoperation for RVOT obstruction and residual muscular
VSD, respectively. The overall survival was $92.1 \%$ at 15 years after repair.

\section{Functional Outcomes and Reintervention}

The median follow-up period was 5.9 years (IQR, 0.1413.7 years). The competing risk analysis for reintervention is shown in Figure 1. Freedom from all reintervention at 5, 10 , and 15 years was $73.7 \%, 69.3 \%$, and $52.8 \%$, respectively. Most reoperations occurred within 2 years of repair. A total of 29 reinterventions (surgery for 22 and catheter for 7 ) were performed in 13 patients $(32 \%$; Table 1$)$. Of these procedures, $12(38 \%)$ in 7 patients were related to the RVOT. The reason for reintervention was RVOT obstruction in 3 patients, pulmonary insufficiency in 2, and both obstruction and insufficiency in 2. Reintervention included PV replacement in 6 patients, RV-PA conduit replacement in 3, and RVOT balloon dilatation or stenting in 3. Freedom from RVOT-related reintervention was significantly greater for patients with a preserved PV $(95.2 \%$ vs $35.0 \%$ at 15 years; $P=.046$; Figure 2). Two reoperations were required for left $\mathrm{AVV}$ regurgitation at 1 year and 13.8 years after surgery. No right AVV reintervention was required. One patient had mild residual left AVV regurgitation and one had moderate left AVV regurgitation. There were no patients in this series who required valve replacement. One patient required LVOT fibromuscular ring resection 1 year after the initial repair. RVOT reconstruction with a nonpreserved PV $(P=.040)$ and a lower PV z-score $(P=.048)$ were identified as risk factors for RVOT-related reintervention.

The latest echocardiogram showed a median RVOT pressure gradient of $25 \mathrm{~mm} \mathrm{Hg}$ (IQR, 12-32 $\mathrm{mm} \mathrm{Hg}$; Table 2). Moderate or more pulmonary insufficiency was seen in 13 patients $(56 \%)$. Two patients $(5 \%)$ had moderate or more AVV regurgitation. Residual LVOT obstruction was noted in 1 patient $(2 \%)$ who underwent LVOT fibromuscular ring resection.

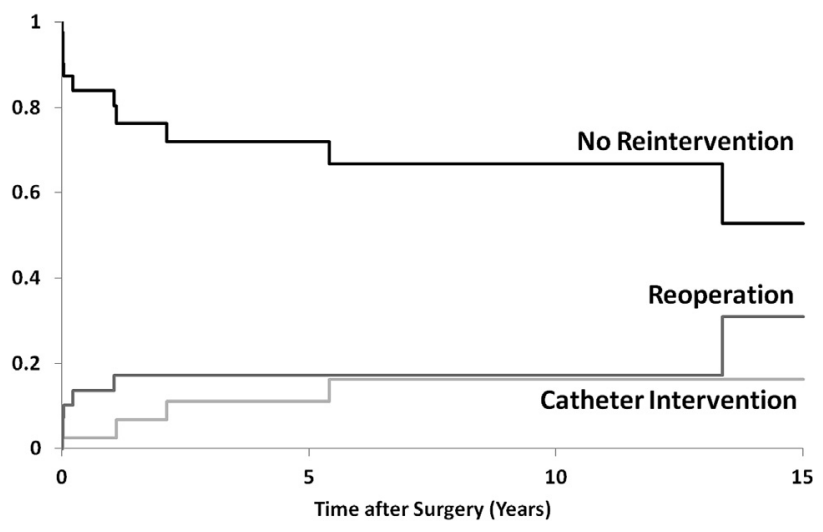

FIGURE 1. Competing risk plot showing clinical outcomes for the entire cohort. 


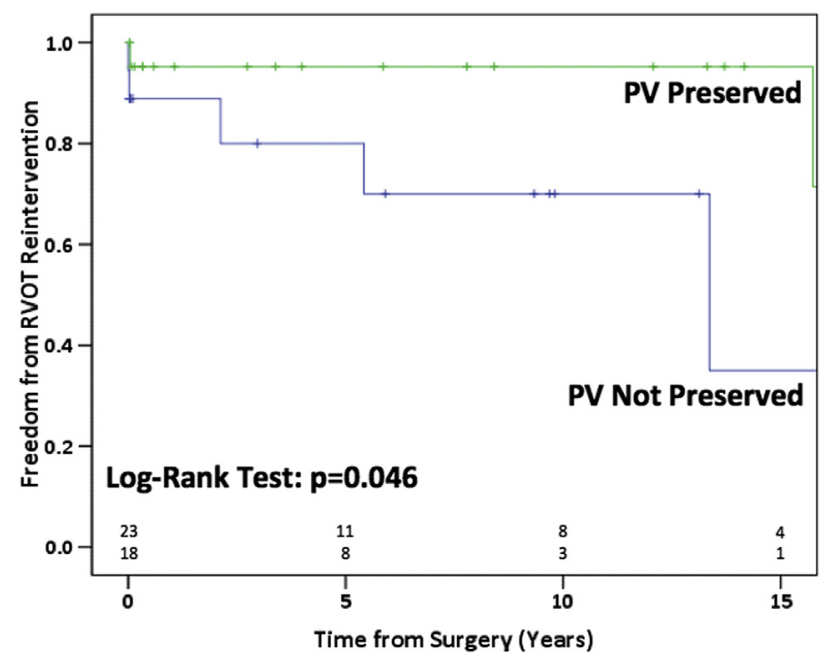

FIGURE 2. Freedom from right ventricular outflow tract (RVOT) reintervention stratified by RVOT reconstruction type. Freedom from RVOT reintervention in pulmonary valve $(P V)$-preserved patients is significantly greater than that of patients with their PVs not preserved.

\section{Case-Match Control: TOF/AVSD Versus Isolated TOF}

No difference was found in body size between the 2 groups. Patient age at surgery was older in the TOF/ AVSD group (19.0 vs 7.95 months; $P=.012$ ). No difference was found in the level of RVOT obstruction between the groups. Most patients in both groups had both subvalvular and valvular stenosis (Table E1). The preoperative RVOT peak pressure gradient was greater in the isolated TOF group (74 vs $65 \mathrm{~mm} \mathrm{Hg} ; P=.023$ ). The TOF/AVSD group required repair with an infundibular patch more often than did the isolated TOF group (11 vs 3 patients; $P=.033$; Table 2). The PV preservation rate was comparable between the groups (TOF/AVSD, 19 [58\%] vs isolated TOF, 24 $[73 \%] ; P=.196)$. Among the patients with a preserved $\mathrm{PV}$, no differences were seen in the preoperative PV z-score between the groups $(-1.94$ vs $-1.62 ; P=.420)$; however, the PV z-score in the TOF/AVSD group was significantly greater than that in the isolated TOF group among the patients with a transannular patch $(P=.014$; Figure 3$)$. The distribution of the $\mathrm{PV} \mathrm{z}$-score in the TOF/AVSD group was equal, regardless of the type of RVOT reconstruction (PV preserved, -1.94 vs $\mathrm{PV}$ not preserved, -2.32; $P=.702)$. In contrast, in the isolated TOF group, the PV Z-score in patients with a preserved PV was significantly greater than that of patients with a transannular patch $(-1.62$ vs $-4.33 ; P=.001)$. The follow-up RVOT peak pressure gradient was greater in the TOF/AVSD group than in the isolated TOF group $(P=.011)$. No difference was found in the severity of pulmonary insufficiency between the 2 groups (Table 2). Freedom from RVOTrelated reintervention was comparable between the 2 groups
TABLE 2. Postoperative case-match control (tetralogy of Fallot)

\begin{tabular}{|c|c|c|c|}
\hline Variable & $\begin{array}{c}\text { TOF/AVSD } \\
(\mathbf{n}=\mathbf{3 3})\end{array}$ & $\begin{array}{c}\text { TOF } \\
(\mathbf{n}=\mathbf{3 3})\end{array}$ & $\begin{array}{c}P \\
\text { value }\end{array}$ \\
\hline \multicolumn{4}{|l|}{ Operative technique } \\
\hline $\begin{array}{l}\text { PV preserved, no } \\
\text { infundibular patch }\end{array}$ & $8(24)$ & $21(64)$ & .001 \\
\hline $\begin{array}{l}\text { PV preserved, } \\
\text { infundibular patch }\end{array}$ & $11(33)$ & $3(9)$ & .033 \\
\hline PV not preserved & $14(42)$ & $9(27)$ & .196 \\
\hline \multicolumn{4}{|l|}{ Discharge echocardiogram } \\
\hline $\begin{array}{l}\text { Age at echocardiogram } \\
\text { (mo) }\end{array}$ & $19.1(10.0-38.6)$ & $8.1(6.3-25.8)$ & .012 \\
\hline $\begin{array}{l}\text { Interval from surgery } \\
\quad(\mathrm{mo})\end{array}$ & $0.23(0.03-0.44)$ & $0.16(0.10-0.26)$ & .434 \\
\hline RVOT gradient & $20(13-27)$ & $16(9-28)$ & .796 \\
\hline \multicolumn{4}{|l|}{ Pulmonary insufficiency } \\
\hline None & $12(36)$ & $5(15)$ & .049 \\
\hline Trivial & $1(3)$ & $6(18)$ & .105 \\
\hline Mild & $4(12)$ & $4(12)$ & 1.000 \\
\hline Mild+ & $3(9)$ & $4(12)$ & 1.000 \\
\hline Moderate & $4(12)$ & $2(6)$ & .672 \\
\hline Severe & $4(12)$ & $12(36)$ & .042 \\
\hline Indeterminate & $5(15)$ & $0(0)$ & .053 \\
\hline $\begin{array}{r}\text { Long-term follow-up } \\
\text { echocardiogram }\end{array}$ & $\mathrm{n}=23$ & $\mathrm{n}=17$ & \\
\hline $\begin{array}{l}\text { Age at echocardiogram } \\
(\mathrm{mo})\end{array}$ & $140.0(60.5-195.7)$ & $33.5(18.7-64.1)$ & .001 \\
\hline $\begin{array}{l}\text { Interval from surgery } \\
\text { (mo) }\end{array}$ & $113.6(24.3 .1-157.8)$ & $1.7(1.1-53.4)$ & .001 \\
\hline RVOT gradient & $25(12-32)$ & $15(9-30)$ & .011 \\
\hline \multicolumn{4}{|l|}{ Pulmonary insufficiency } \\
\hline None & $1(4)$ & $0(0)$ & 1.000 \\
\hline Trivial & $2(9)$ & $3(18)$ & .634 \\
\hline Mild & $5(22)$ & $5(29)$ & .717 \\
\hline Mild+ & $2(9)$ & $3(18)$ & .634 \\
\hline Moderate & $3(13)$ & $2(12)$ & 1.000 \\
\hline Severe & $10(43)$ & $4(23)$ & .315 \\
\hline
\end{tabular}

Data presented as median (interquartile range) or $\mathrm{n}(\%) . T O F$, Tetralogy of Fallot; $A V S D$, atrioventricular septal defect; $P V$, pulmonary valve; $R V O T$, right ventricular outflow tract.

(TOF/AVSD, $88.6 \%$ vs isolated TOF, $83.9 \%$ at 5 years; $P=.809 ;$ Figure $4, A)$.

\section{Case-Match Control: TOF/AVSD Versus Isolated AVSD}

Patient age at surgery was older in the TOF/AVSD group than in the isolated AVSD group (19.0 vs 5.5 months; $P<.001)$. The AVV index was comparable between the 2 groups. No difference was seen in the overall severity of preoperative AVV regurgitation between the groups, although a nonsignificant trend toward more moderate AVV regurgitation was present in the TOF/AVSD group (Table E2). The indexed left and right AVV diameters and left and right ventricular size were larger in the patients with isolated AVSD $(P<.001)$. No preoperative LVOT stenosis was present in either group. The isolated AVSD group tended to have more right $\mathrm{AVV}$ regurgitation at discharge 


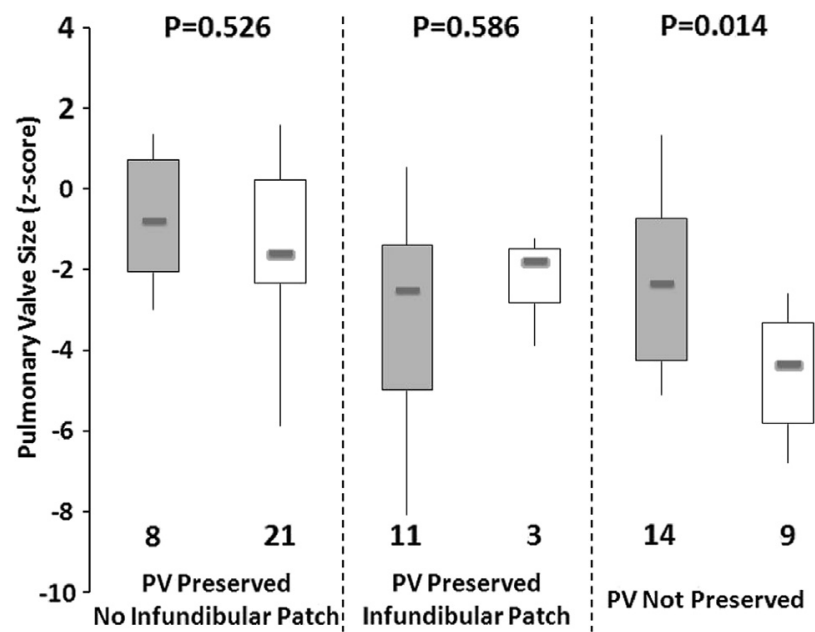

FIGURE 3. Relationship between preoperative pulmonary valve $(P V)$ size and right ventricular outflow tract (RVOT) reconstruction for patients with TOF/AVSD compared with isolated tetralogy of Fallot. Numbers shown below boxes represent proportion of each category. The top and bottom of the boxes represent the 25th and 75th percentile (interquartile range), respectively. The horizontal line represents the median. The top vertical lines represent the maximum value and the bottom vertical lines represent the minimum values. Gray indicates patients with tetralogy of Fallot/atrioventricular septal defect; white, patients with isolated tetralogy of Fallot.

$(P=.053)$, but no difference was seen in the AVV regurgitation grades between the groups at the latest follow-up examination (Table 3). Freedom from AVV/LVOT-related reintervention was comparable between the 2 groups (TOF/AVSD, $95.2 \%$ vs isolated AVSD, $86.0 \%$ at 5 years; $P=.332$; Figure $4, B)$.

\section{DISCUSSION}

Repair of TOF/AVSD involves reconstruction of both inlet and outlet portions of the ventricles, which resulted in high operative mortality in the early era. A better understanding of the anatomy and physiology and the introduction of primary repair in infancy have significantly improved survival. ${ }^{3,5,8-10}$ Our interest has shifted toward investigating the long-term functional outcomes, because this entity potentially has the dual late hazard of an RVOT or AVVs that can become stenosed, obstructed, or dysfunctional. This study attempted to analyze the long-term functional outcomes of the inlet and outlet components separately by applying a double case-match control methodology. The late survival in this cohort was excellent ( $92 \%$ at 15 years). Survival was consistent with that from other recent series. ${ }^{5,8-10,17}$ Approximately one third of the cohort required some form of reintervention by 10 years postoperatively. Reintervention was mainly performed on the RVOT. AVV and LVOT reinterventions were rare. Despite having similar preoperative $\mathrm{PV}$ z-scores and lower RVOT pressure gradients, the TOF/AVSD group required repair with a transannular patch more often than
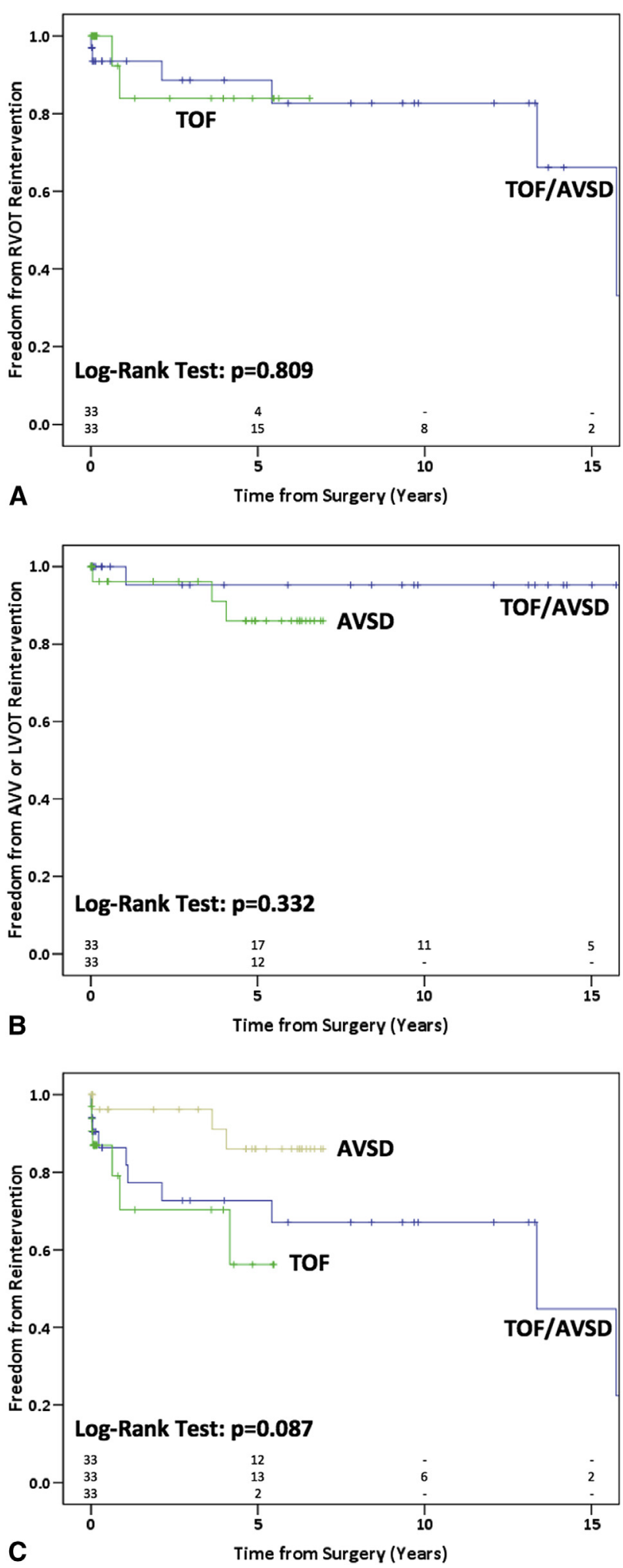

FIGURE 4. Freedom from reintervention between our cohort and casematched controls. A, Right ventricular outflow tract (RVOT)-related reintervention. B, atrioventricular valve $(A V V) /$ left ventricular outflow tract (LVOT) reintervention. C, All reinterventions. 
TABLE 3. Postoperative case-match control (atrioventricular septal defect)

\begin{tabular}{|c|c|c|c|}
\hline Variable & $\begin{array}{c}\text { TOF/AVSD } \\
(\mathbf{n}=\mathbf{3 3})\end{array}$ & $\begin{array}{c}\text { AVSD } \\
(\mathbf{n}=\mathbf{3 3})\end{array}$ & $\begin{array}{c}P \\
\text { value }\end{array}$ \\
\hline \multicolumn{4}{|l|}{ Discharge echocardiogram } \\
\hline $\begin{array}{l}\text { Age at echocardiogram } \\
\text { (mo) }\end{array}$ & $19.1(10.0-38.6)$ & $5.9(5.3-6.9)$ & $<.001$ \\
\hline $\begin{array}{l}\text { Interval from surgery } \\
\text { (mo) }\end{array}$ & $0.23(0.03-0.44)$ & $0.25(0.16-0.38)$ & .572 \\
\hline \multicolumn{4}{|l|}{ LVOT obstruction } \\
\hline Yes & $2(6)$ & $1(3)$ & 1.000 \\
\hline No & $29(88)$ & $31(94)$ & .672 \\
\hline Indeterminate & $2(6)$ & $1(3)$ & 1.000 \\
\hline \multicolumn{4}{|l|}{ Right AVV regurgitation } \\
\hline None & $7(21)$ & $3(9)$ & .170 \\
\hline Trivial & $5(15)$ & $5(15)$ & 1.000 \\
\hline Mild & $16(48)$ & $16(48)$ & 1.000 \\
\hline Mild + & $3(9)$ & $3(9)$ & 1.000 \\
\hline Moderate & $0(0)$ & $5(15)$ & .053 \\
\hline Indeterminate & $2(6)$ & $1(3)$ & 1.000 \\
\hline \multicolumn{4}{|l|}{ Left AVV regurgitation } \\
\hline None & $10(30)$ & $1(3)$ & .006 \\
\hline Trivial & $1(3)$ & $4(12)$ & .355 \\
\hline Mild & $18(55)$ & $19(58)$ & .804 \\
\hline Mild+ & $2(6)$ & $5(15)$ & .427 \\
\hline Moderate & $0(0)$ & $3(9)$ & .238 \\
\hline Indeterminate & $2(6)$ & $1(3)$ & 1.000 \\
\hline $\begin{array}{l}\text { Long-term follow-up } \\
\text { echocardiogram }\end{array}$ & $\mathrm{n}=23$ & $\mathrm{n}=22$ & \\
\hline $\begin{array}{l}\text { Age at echocardiogram } \\
\text { (mo) }\end{array}$ & $140.0(60.5-195.7)$ & $65.2(47.7-74.9)$ & .004 \\
\hline $\begin{array}{l}\text { Interval from surgery } \\
\quad(\mathrm{mo})\end{array}$ & $113.6(24.3-157.8)$ & $57.1(43.3-69.5)$ & .048 \\
\hline \multicolumn{4}{|l|}{ LVOT obstruction } \\
\hline Yes & $1(4)$ & $0(0)$ & 1.000 \\
\hline No & $22(96)$ & $22(100)$ & 1.000 \\
\hline \multicolumn{4}{|l|}{ Right AVV regurgitation } \\
\hline None & $8(35)$ & $2(9)$ & .071 \\
\hline Trivial & $0(0)$ & $4(18)$ & .049 \\
\hline Mild & $13(57)$ & $12(55)$ & .894 \\
\hline Mild+ & $1(4)$ & $2(9)$ & .608 \\
\hline Moderate & $1(4)$ & $2(9)$ & .608 \\
\hline \multicolumn{4}{|l|}{ Left AVV regurgitation } \\
\hline None & $3(13)$ & $1(5)$ & .608 \\
\hline Trivial & $2(9)$ & $4(18)$ & .414 \\
\hline Mild & $13(57)$ & $12(55)$ & .894 \\
\hline Mild+ & $2(9)$ & $1(5)$ & 1.000 \\
\hline Moderate & $2(9)$ & $2(9)$ & 1.000 \\
\hline Moderate + & $0(0)$ & $1(5)$ & .489 \\
\hline Severe & $0(0)$ & $1(5)$ & .489 \\
\hline Indeterminate & $1(4)$ & $0(0)$ & 1.000 \\
\hline
\end{tabular}

Data presented as median (interquartile range) or $\mathrm{n}(\%) . T O F$, Tetralogy of Fallot; $A V S D$, atrioventricular septal defect; $L V O T$, left ventricular outflow tract; $A V V$, atrioventricular valve.

the isolated TOF group. The preoperative AVV/LVOT anatomy and physiology and long-term AVV/LVOT function after repair were comparable to those of the isolated
AVSD group. Freedom from all reintervention in the TOF/AVSD group was slightly lower than that in the isolated AVSD group and almost identical to that of the isolated TOF group $(P=.087$; Figure $4, C)$.

\section{RVOT Reconstruction: Effect of Preoperative Anatomy and Physiology}

The anatomy and dimensions of the RVOT and the mode of RVOT obstruction in the TOF/AVSD group were very similar to those in the isolated TOF group. The preoperative RVOT peak pressure gradient across the RVOT was lower in the TOF/AVSD group than in the isolated TOF group, for which we found no clear explanation. Despite having a PV size similar to that of the isolated TOF group, this study showed a significantly lower rate of $\mathrm{PV}$ annulus preservation with a high incidence of infundibular patch use in the TOF/AVSD group. In the past, transannular patch repair was performed even in patients with a reasonable $\mathrm{PV}$ annulus z-score in the TOF/AVSD group. A greater correlation was found between the preoperative PV size and the need for transannular incision in the isolated TOF group, indicating that the preoperative PV size predicts RVOT reconstruction.

First, this was partly because of our evolving institutional strategy in the past 2 decades, in which we attempted more PV-preserving surgery combined with placement of an infundibular patch. ${ }^{18}$ Only 9 of the 33 patients $(27 \%)$ in the cohort who were available for the echocardiographic analysis had a PV z-score of less than -4 . One could speculate that we might be able to achieve a PV annulus preservation rate close to $70 \%$ with our current strategy. In addition, a transannular or infundibular incision was often used to expose the anteriorly deviated VSD, which might have increased the likelihood of a non-PV-preserved repair. ${ }^{2,3,8-10}$ Overall, approximately $30 \%$ of the cohort had unfavorable RVOT anatomy for PV preservation surgery. The PV preservation rate in this cohort was $56 \%$, significantly greater than that in other series, which had PV preservation rates ranging from $13 \%$ to $21 \%{ }^{9,10}$ From the anatomic observation and our current strategy of using the infundibular patch technique, we believe that a PV preservation rate of $70 \%$ could be achievable in this entity.

\section{RVOT Reintervention}

Our study showed superior outcomes in RVOT-related reintervention in PV-preserved patients, with freedom from reintervention of $95.2 \%$ at 15 years compared with $35 \%$ in non-PV-preserved patients. Shuhaiber and colleagues ${ }^{9}$ reported that the use of conduits required a greater RVOT reintervention rate than other types of reconstruction, such as transannular and infundibular patches. Brancaccio and colleagues ${ }^{10}$ showed consistent findings, with freedom from reintervention of $62.2 \%$ at 10 years in the nonconduit 
group compared with $14.0 \%$ in the conduit group. Among 7 patients who received an artificial valve or conduit at the initial repair in the present series, our retrospective review revealed 6 patients who could have undergone transannular patch repair (1 patient had an abnormal coronary artery crossing the RVOT, which necessitated conduit placement). These findings underscore the importance of PV preservation and avoidance of an artificial valve or conduit to minimize or delay RVOT reintervention. However, it is important to mention that the RVOT reintervention profile in the patients with TOF/AVSD in this series was equivalent to what was achieved in patients with isolated TOF.

\section{AVV in Patients With TOF/AVSD}

The striking difference between the hearts with TOF/ AVSD and isolated AVSD was the ventricular and AVV dimensions. Because of the presence of RVOT obstruction and subsequent lower pulmonary/systemic flow ratio, the size of both the ventricles and the AVVs in those with TOF/AVSD was considerably smaller than the size in the isolated "volume-loaded" AVSD hearts. No difference was seen in overall degree of preoperative AVV regurgitation, although 8 patients with TOF/AVSD had moderate AVV regurgitation preoperatively. This could be explained in part by the late timing of repair in the early era. AVV regurgitation could have developed over time while the patient was awaiting definitive repair (5 of 8 patients underwent repair at $\geq 1$ year old). The adverse effect of a systemic-to-pulmonary shunt and subsequent volume overload on AVV function has been well described, ${ }^{7}$ although only 1 of 8 patients had undergone a previous shunt procedure. It is also possible that the presence of RVOT obstruction (ie, increase in afterload) might have some adverse effect on AVV competency. However, the early and late AVV function in patients with TOF/AVSD was excellent. The mechanism and timing of left AVV reintervention was nonspecific. Significant pulmonary insufficiency or residual RVOT obstruction had no specific adverse effects on the right AVV during the median follow-up of 5.9 years; however, the long-term effect of chronic pulmonary insufficiency on right AVV function has not been determined.

\section{LVOT in Patients With TOF/AVSD}

The LVOT dimensions in those with TOF/AVSD were significantly smaller than those in patients with isolated AVSD. An overriding aorta in the presence of an AVSDtype VSD might pose the threat of potential acute and chronic LVOT obstruction. All patients in the present series received a comma-shape VSD patch to avoid LVOT obstruction. No acute LVOT obstruction developed, and the 1 incidence of LVOT reintervention was not related to the patch configuration but, rather, to an isolated fibromuscular ring. No significant LVOT pressure gradient was noted in the latest follow-up examination. Overall, the LVOT in those with TOF/AVSD has had favorable long-term outcomes.

\section{Study Limitations}

The main limitation of this study was its retrospective nature. The surgical techniques and postoperative management have evolved significantly in the past 2 decades, which influenced the clinical outcomes in our cohort. Also, the present study did not focus on the preoperative RVOT dimensions, which could have had an effect on the type of repair and subsequent RVOT functional outcomes.

\section{CONCLUSIONS}

The results of our study have shown that late survival and functional outcomes after repair of TOF/AVSD are excellent. PV preservation and the avoidance of an artificial conduit were related to greater freedom from RVOT reintervention. The preoperative RVOT and AVV anatomy and physiology in those with TOF/AVSD are similar to those in patients with isolated TOF and isolated AVSD, respectively. The long-term AVV and LVOT function in the present cohort were excellent. In the current era, the surgically modified history of TOF/AVSD was not significantly different from that of either isolated TOF or isolated AVSD.

The authors thank Dr Anusha Jegatheeswaran for her kind assistance.

\section{References}

1. Gatzoulis MA, Shore D, Yacoub M, Shinebourne EA. Complete atrioventricular septal defect with tetralogy of Fallot: diagnosis and management. Br Heart J. 1994;71:579-83

2. Uretzky G, Puga FJ, Danielson GK, Feldt RH, Julsrud PR, Seward JB, et al. Complete atrioventricular canal associated with tetralogy of Fallot: morphologic and surgical considerations. J Thorac Cardiovasc Surg. 1984;87: 756-66.

3. Ricci M, Tchervenkov CI, Jacobs JP, Anderson RH, Cohen G, Bove EL. Surgical correction for patients with tetralogy of Fallot and common atrioventricular junction. Cardiol Young. 2008;18(suppl 3):29-38.

4. Pacifico AD, Kirklin JW, Bargeron LM Jr. Repair of complete atrioventricular canal associated with tetralogy of Fallot or double-outlet right ventricle: report of 10 patients. Ann Thorac Surg. 1980;29:351-6.

5. Najm HK, Van Arsdell GS, Watzka S, Hornberger L, Coles JG, Williams WG. Primary repair is superior to initial palliation in children with atrioventricular septal defect and tetralogy of Fallot. J Thorac Cardiovasc Surg. 1998;116: 905-13.

6. Vargas FJ, Coto EO, Mayer JE Jr, Jonas RA, Castaneda AR. Complete atrioventricular canal and tetralogy of Fallot: surgical considerations. Ann Thorac Surg. 1986;42:258-63

7. Karl TR. Atrioventricular septal defect with tetralogy of Fallot or double-outlet right ventricle: surgical considerations. Semin Thorac Cardiovasc Surg. 1997;9: 26-34.

8. Prifti E, Bonacchi M, Bernabei M, Leacche M, Bartolozzi F, Murzi B, et al. Repair of complete atrioventricular septal defect with tetralogy of Fallot: our experience and literature review. J Card Surg. 2004;19:175-83.

9. Shuhaiber JH, Robinson B, Gauvreau K, Breitbart R, Mayer JE, Del Nido PJ, et al. Outcome after repair of atrioventricular septal defect with tetralogy of Fallot. J Thorac Cardiovasc Surg. 2012;143:338-43

10. Brancaccio G, Michielon G, Filippelli S, Perri G, Di Carlo D, Iorio FS, et al. Transannular patching is a valid alternative for tetralogy of Fallot and complete 
atrioventricular septal defect repair. J Thorac Cardiovasc Surg. 2009;137: 919-23.

11. Padalino MA, Vida VL, Stellin G. Transatrial-transpulmonary repair of tetralogy of Fallot. Semin Thorac Cardiovasc Surg Pediatr Card Surg Annu. 2009;48-53

12. Jonas RA. Early primary repair of tetralogy of Fallot. Semin Thorac Cardiovasc Surg Pediatr Card Surg Annu. 2009;39-47.

13. Hirsch JC, Mosca RS, Bove EL. Complete repair of tetralogy of Fallot in the neonate: results in the modern era. Ann Surg. 2000;232:508-14.

14. Bakhtiary F, Takacs J, Cho MY, Razek V, Dahnert I, Doenst T, et al. Long-term results after repair of complete atrioventricular septal defect with two-patch technique. Ann Thorac Surg. 2010;89:1239-43
15. Suzuki T, Bove EL, Devaney EJ, Ishizaka T, Goldberg CS, Hirsch JC, et al. Results of definitive repair of complete atrioventricular septal defect in neonates and infants. Ann Thorac Surg. 2008;86:596-602.

16. Cohen MS, Jacobs ML, Weinberg PM, Rychik J. Morphometric analysis of unbalanced common atrioventricular canal using two-dimensional echocardiography. J Am Coll Cardiol. 1996;28:1017-23.

17. O’Blenes SB, Ross DB, Nanton MA, Murphy DA. Atrioventricular septal defect with tetralogy of Fallot: results of surgical correction. Ann Thorac Surg. 1998;66: 2078-82; discussion 82-4

18. Van Arsdell GS, Maharaj GS, Tom J, Rao VK, Coles JG, Freedom RM, et al. What is the optimal age for repair of tetralogy of Fallot? Circulation. 2000; 102(19 suppl 3):III123-9.

Access to The Journal of Thoracic and Cardiovascular Surgery Online is reserved for print subscribers!

Full-text access to The Journal of Thoracic and Cardiovascular Surgery Online is available for all print subscribers. To activate your individual online subscription, please visit The Journal of Thoracic and Cardiovascular Surgery Online, point your browser to http://www.mosby.com/itcvs, follow the prompts to activate your online access, and follow the instructions. To activate your account, you will need your subscriber account number, which you can find on your mailing label (note: the number of digits in your subscriber account number varies from 6 to 10). See the example below in which the subscriber account number has been circled:

\section{Sample mailing label}

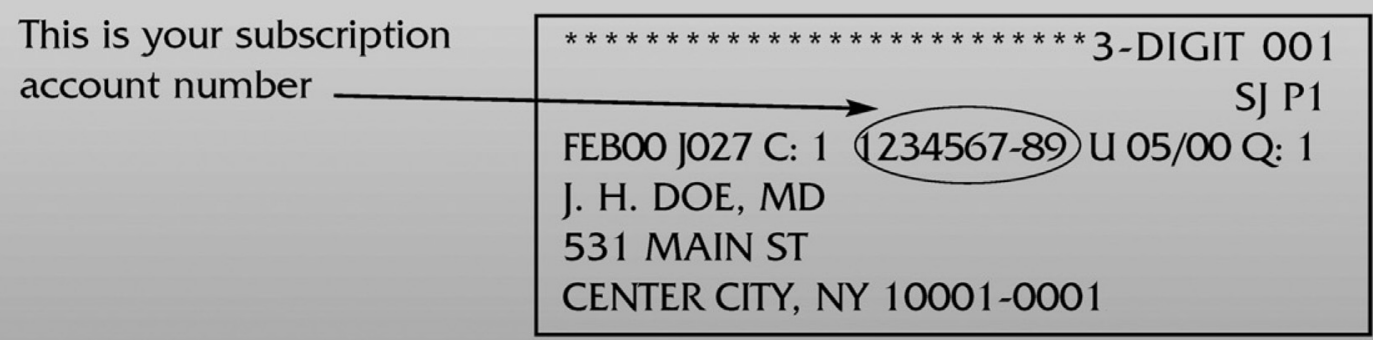

Personal subscriptions to The Journal of Thoracic and Cardiovascular Surgery Online are for individual use only and may not be transferred. Use of The Journal of Thoracic and Cardiovascular Surgery Online is subject to agreement to the terms and conditions as indicated online. 
TABLE E1. Preoperative case-match control (tetralogy of Fallot)

\begin{tabular}{|c|c|c|c|}
\hline Variable & TOF/AVSD $(n=33)$ & TOF $(n=33)$ & $P$ value \\
\hline Weight $(\mathrm{kg})$ & $7.9(5.2-10.6)$ & $8.5(6.2-10.19)$ & .428 \\
\hline $\operatorname{BSA}\left(\mathrm{m}^{2}\right)$ & $0.44(0.31-0.52)$ & $0.39(0.31-0.49)$ & .547 \\
\hline Interval from echocardiography to surgery (mo) & $2.3(1.1-4.4)$ & $0.72(0.23-1.48)$ & $<.001$ \\
\hline Age at surgery $(\mathrm{mo})$ & $19.0(10.3-36.2)$ & $7.95(6.14-25.69)$ & .012 \\
\hline Weight at surgery $(\mathrm{kg})$ & $10.0(6.5-12.5)$ & $9.0(6.8-10.6)$ & .401 \\
\hline BSA at surgery $\left(\mathrm{m}^{2}\right)$ & $0.47(0.39-0.52)$ & $0.46(0.40-0.49)$ & .621 \\
\hline \multicolumn{4}{|l|}{ VSD morphology } \\
\hline \multicolumn{4}{|l|}{ VSD size } \\
\hline Small & $1(3)$ & $1(3)$ & 1.000 \\
\hline Medium & $2(6)$ & $4(12)$ & .672 \\
\hline Large & $30(91)$ & $28(85)$ & .708 \\
\hline Nonrestrictive VSD & $33(100)$ & $30(91)$ & .238 \\
\hline VSD direction of flow in systole (left to right) & $33(100)$ & $33(100)$ & - \\
\hline \multicolumn{4}{|l|}{ Additional VSD } \\
\hline Yes & $1(3)$ & $0(0)$ & 1.000 \\
\hline No & $25(76)$ & $33(100)$ & .005 \\
\hline Indeterminate & $7(21)$ & $0(0)$ & .011 \\
\hline \multicolumn{4}{|l|}{ RVOT } \\
\hline PV annulus $(\mathrm{cm})$ & $0.89(0.74-1.00)$ & $0.87(0.76-0.97)$ & .883 \\
\hline Indexed $\mathrm{PV}$ annulus $\left(\mathrm{cm} / \mathrm{m}^{2}\right)$ & $2.16(1.68-2.72)$ & $2.16(1.73-2.90)$ & .837 \\
\hline PV z-score & $-2.25(-3.37$ to 0.13$)$ & $-2.13(-3.43$ to -0.54$)$ & .822 \\
\hline \multicolumn{4}{|l|}{ PV regurgitation } \\
\hline None & $23(70)$ & $26(79)$ & .574 \\
\hline Trivial & $1(3)$ & $5(15)$ & .197 \\
\hline Mild & $6(18)$ & $2(6)$ & .258 \\
\hline Indeterminate & $3(9)$ & $0(0)$ & .238 \\
\hline Outflow tract obstruction & $33(100)$ & $33(100)$ & - \\
\hline \multicolumn{4}{|l|}{ Obstruction level } \\
\hline Subvalve & $31(94)$ & $31(94)$ & 1.000 \\
\hline Valve & $32(97)$ & $32(97)$ & 1.000 \\
\hline Supravalve & $8(24)$ & $13(39)$ & .290 \\
\hline PAs & $1(3)$ & $1(3)$ & .613 \\
\hline Peak gradient (mm Hg) & $65(55-75)$ & $74(65-85)$ & .023 \\
\hline Right PA size $(\mathrm{cm})$ & $0.64(0.56-0.76)$ & $0.65(0.55-0.76)$ & .883 \\
\hline Right PA indexed $\left(\mathrm{cm} / \mathrm{m}^{2}\right)$ & $1.59(1.29-1.80)$ & $1.55(1.38-1.93)$ & .509 \\
\hline Left PA size $(\mathrm{cm})$ & $0.60(0.48-0.75)$ & $0.66(0.51-0.69)$ & .934 \\
\hline Left PA indexed $\left(\mathrm{cm} / \mathrm{m}^{2}\right)$ & $1.39(1.25-1.71)$ & $1.44(1.27-1.74)$ & .542 \\
\hline
\end{tabular}

Data presented as median (interquartile range) or n (\%). TOF, Tetralogy of Fallot; $A V S D$, atrioventricular septal defect; $B S A$, body surface area; VSD, ventricular septal defect; $R V O T$, right ventricular outflow tract; $P V$, pulmonary valve; $P A$, pulmonary artery. 
TABLE E2. Preoperative case-match control (atrioventricular septal defect)

\begin{tabular}{|c|c|c|c|}
\hline Variable & TOF/AVSD $(\mathbf{n}=\mathbf{3 3})$ & $\operatorname{AVSD}(\mathbf{n}=\mathbf{3 3})$ & $P$ value \\
\hline Weight (kg) & $7.9(5.2-10.6)$ & $4.5(3.3-5.5)$ & $<.001$ \\
\hline $\operatorname{BSA}\left(\mathrm{m}^{2}\right)$ & $0.44(0.31-0.52)$ & $0.25(0.21-0.28)$ & $<.001$ \\
\hline Interval from echocardiography to surgery (mo) & $2.3(1.1-4.4)$ & $1.0(0.3-4.5)$ & .124 \\
\hline Age at surgery (mo) & $19.0(10.3-36.2)$ & $5.5(4.9-6.7)$ & $<.001$ \\
\hline Weight at surgery $(\mathrm{kg})$ & $10.0(6.5-12.5)$ & $5.6(5.1-6.1)$ & $<.001$ \\
\hline BSA at surgery $\left(\mathrm{m}^{2}\right)$ & $0.47(0.39-0.52)$ & $0.32(0.30-0.35)$ & $<.001$ \\
\hline \multicolumn{4}{|l|}{ Right versus left morphology } \\
\hline \multicolumn{4}{|l|}{ Ventricular dominance } \\
\hline RV & $4(12)$ & $3(9)$ & 1.000 \\
\hline LV & $0(0)$ & $2(6)$ & .492 \\
\hline None & $29(88)$ & $28(85)$ & 1.000 \\
\hline Angle RV inflow-to-LV inflow $\left(^{\circ}\right)$ & $96(85-107)$ & $137(110-146)$ & $<.001$ \\
\hline AVV size $(\mathrm{cm})$ & $3.51(2.92-3.83)$ & $2.30(1.90-2.60)$ & $<.001$ \\
\hline Indexed right $\mathrm{AVV}$ area $\left(\mathrm{cm}^{2} / \mathrm{m}^{2}\right)$ & $7.66(6.57-8.92)$ & $7.84(6.69-9.65)$ & .479 \\
\hline Indexed left AVV area $\left(\mathrm{cm}^{2} / \mathrm{m}^{2}\right)$ & $6.85(5.57-7.56)$ & $7.20(5.95-9.12)$ & .203 \\
\hline Indexed total AVV area $\left(\mathrm{cm}^{2} / \mathrm{m}^{2}\right)$ & $14.42(12.55-16.30)$ & $15.00(12.38-18.42)$ & .352 \\
\hline AVV index & $0.47(0.45-0.48)$ & $0.48(0.46-0.50)$ & .098 \\
\hline \multicolumn{4}{|l|}{ ASD morphology } \\
\hline \multicolumn{4}{|l|}{ Ostium primum ASD } \\
\hline Yes & $32(97)$ & $32(97)$ & 1.000 \\
\hline No & $0(0)$ & $0(0)$ & - \\
\hline Indeterminate & $1(3)$ & $1(3)$ & 1.000 \\
\hline \multicolumn{4}{|l|}{ Restrictive primum ASD } \\
\hline Yes & $2(6)$ & $1(3)$ & 1.000 \\
\hline No & $29(88)$ & $31(94)$ & .672 \\
\hline Indeterminate & $2(6)$ & $1(3)$ & 1.000 \\
\hline \multicolumn{4}{|l|}{ Additional ASD } \\
\hline Yes & $9(27)$ & $26(79)$ & $<.001$ \\
\hline No & $9(27)$ & $4(12)$ & .215 \\
\hline Indeterminate & $15(45)$ & $3(9)$ & .002 \\
\hline \multicolumn{4}{|l|}{ VSD morphology } \\
\hline \multicolumn{4}{|l|}{ Inlet VSD size } \\
\hline Small & $1(3)$ & $2(6)$ & 1.000 \\
\hline Medium & $2(6)$ & $2(6)$ & 1.000 \\
\hline Large & $30(91)$ & $29(88)$ & 1.000 \\
\hline \multicolumn{4}{|l|}{ Restrictive inlet VSD } \\
\hline Yes & $0(0)$ & $2(6)$ & .492 \\
\hline No & $33(100)$ & $29(88)$ & .114 \\
\hline Indeterminate & $0(0)$ & $2(6)$ & .492 \\
\hline \multicolumn{4}{|l|}{ Inlet VSD direction of flow in systole } \\
\hline Left to right & $33(100)$ & $29(88)$ & .114 \\
\hline Indeterminate & $0(0)$ & $4(12)$ & .114 \\
\hline \multicolumn{4}{|l|}{ Additional VSD } \\
\hline Yes & $1(3)$ & $3(9)$ & .613 \\
\hline No & $25(76)$ & $20(61)$ & .186 \\
\hline Indeterminate & $7(21)$ & $10(30)$ & .398 \\
\hline \multicolumn{4}{|l|}{ AVSD morphology } \\
\hline \multicolumn{4}{|l|}{ Rastelli type } \\
\hline A & $4(12)$ & $25(76)$ & $<.001$ \\
\hline $\mathrm{C}$ & $29(88)$ & $4(12)$ & $<.001$ \\
\hline Indeterminate & $0(0)$ & $0(0)$ & .114 \\
\hline
\end{tabular}


TABLE E2. Continued

Variable

TOF/AVSD $(\mathbf{n}=\mathbf{3 3})$

$\operatorname{AVSD}(\mathbf{n}=33)$

$P$ value

AVV regurgitation

Right AVV regurgitation

None

10 (29)

10 (29)

Trivial

9 (26)

Mild

3 (9)

Moderate

1 (3)

Indeterminate

1 (3)

Left AVV regurgitation

None

Trivial

8 (24)

9 (26)

9 (26)

Mild

Moderate

8 (24)

Severe

Indeterminate

$0(0)$

$0(0)$

6 (18)

9 (27)

$12(36)$

4 (12)

1 (3)

$1(3)$

$18(55)$

7 (12)

3 (9)

$0(0)$

$1(3)$

.251

Central AVV regurgitation

$29(85)$

$0(0)$

$3(9)$

$0(0)$

Moderate

$0(0)$

Severe

$2(6)$

$26(79)$

.786

.428

1.000

1.000

1.000

Indeterminate

Diameter $(\mathrm{cm})$

Color inflow diameter at annulus $(\mathrm{cm})$

Indexed color inflow diameter at annulus $\left(\mathrm{cm} / \mathrm{m}^{2}\right)$

Diameter $(\mathrm{cm})$

Indexed diameter $\left(\mathrm{cm} / \mathrm{m}^{2}\right)$

Color inflow diameter at annulus $(\mathrm{cm})$

Indexed color inflow diameter at annulus $\left(\mathrm{cm} / \mathrm{m}^{2}\right)$

$0(0)$

$1(3)$

4 (12)

$1(3)$

$1(3)$

.012

.215

.769

.185

$-$

1.000

Papillary muscle abnormalities

.322

$-$

.613

.114

1.000

1.000

The categories are:

Yes

No

2 (6)

28 (85)

3 (9)

Right ventricle

Ventricular dysfunction

Yes

No

Apex forming

Length $(\mathrm{cm})$

Indexed length $\left(\mathrm{cm} / \mathrm{m}^{2}\right)$

Width $(\mathrm{cm})$

Indexed width $\left(\mathrm{cm} / \mathrm{m}^{2}\right)$

Left ventricle

Ventricular dysfunction

Apex forming

Length $(\mathrm{cm})$

Indexed length $\left(\mathrm{cm} / \mathrm{m}^{2}\right)$

Width $(\mathrm{cm})$

Indexed width $\left(\mathrm{cm} / \mathrm{m}^{2}\right)$

0 (0)

$33(100)$

33 (100)

$$
0 \text { (0) }
$$

$2.30(2.02-2.64)$

$5.56(4.90-6.47)$

1.83 (1.53-1.99)

4.13 (3.67-4.88)

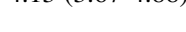

$1.92(1.61-2.23)$

$4.55(3.98-5.44)$

$1.52(1.38-1.78)$

3.77 (3.05-4.56)

$1.79(1.57-1.93)$

7.09 (6.67-7.36)

$1.46(1.29-1.67)$

$5.76(5.18-6.16)$

1.44 (1.28-1.62)

$5.71(5.32-6.15)$

$1.22(1.02-1.28)$

4.72 (4.18-5.08)

$<.001$

$<.001$

.001

$<.001$

$<.001$

$<.001$

$<.001$

$<.001$

$3.57(3.39-3.94)$

8.42 (7.51-10.07)

$1.96(1.76-2.32)$

4.88 (4.12-6.12)

33 (100)

$3.41(3.15-3.89)$

$8.07(7.52-9.77)$

$1.79(1.55-2.15)$

4.59 (3.83-5.72)
1 (3)

31 (94)

1 (3)

1.000

.427

.613

1.000

1 (3)

32 (97)

33 (100)

$2.90(2.46-3.19)$

-

11.19 (10.58-11.92)

$1.80(1.55-2.15)$

6.96 (6.28-7.96)

$<.001$

.059

$<.001$

$0(0)$

33 (100)

$3.09(2.77-3.49)$

$12.15(11.40-13.24)$

1.65 (1.46-1.93)

$6.62(6.12-7.37)$

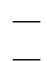

.005

$<.001$

.116

$<.001$ 
TABLE E2. Continued

\begin{tabular}{|c|c|c|c|}
\hline Variable & TOF/AVSD $(\mathbf{n}=\mathbf{3 3})$ & $\operatorname{AVSD}(\mathbf{n}=33)$ & $P$ value \\
\hline \multicolumn{4}{|l|}{ LVOT } \\
\hline Aortic annulus (cm) & $1.39(1.13-1.64)$ & $0.80(0.70-0.88)$ & $<.001$ \\
\hline Indexed aortic annulus $\left(\mathrm{cm} / \mathrm{m}^{2}\right)$ & $3.36(2.71-3.94)$ & $3.16(2.87-3.33)$ & .251 \\
\hline LVOT diameter $(\mathrm{cm})$ & $1.04(0.95-1.32)$ & $0.81(0.75-0.90)$ & $<.001$ \\
\hline Indexed LVOT diameter $\left(\mathrm{cm} / \mathrm{m}^{2}\right)$ & $2.78(2.30-3.28)$ & $3.24(2.88-3.54)$ & .006 \\
\hline \multicolumn{4}{|l|}{ Aortic valve regurgitation } \\
\hline None & $28(85)$ & $31(94)$ & .427 \\
\hline Trivial & $4(12)$ & $0(0)$ & .114 \\
\hline Mild & $1(3)$ & $2(6)$ & 1.000 \\
\hline Outflow tract obstruction & $0(0)$ & $0(0)$ & - \\
\hline Stenosis & $0(0)$ & $0(0)$ & - \\
\hline \multicolumn{4}{|l|}{ Associated cardiac lesions } \\
\hline Septal malalignment & $1(3)$ & $1(3)$ & 1.000 \\
\hline Override & $4(12)$ & $3(9)$ & 1.000 \\
\hline
\end{tabular}

